\title{
GMR
}

\section{Fis isint}

\section{Analysis of gene expression patterns and levels in maize hybrids and their parents}

\author{
H.S. Nie*, S.P. Li*, X.H. Shan, Y. Wu, S.Z. Su, H.K. Liu, J.Y. Han \\ and Y.P. Yuan \\ College of Plant Science, Jilin University, Changchun, China \\ *These authors contributed equally to this study. \\ Corresponding author: Y.P. Yuan \\ E-mail: yuanyp@jlu.edu.cn
}

Genet. Mol. Res. 14 (4): 15399-15411 (2015)

Received July 10, 2015

Accepted September 28, 2015

Published November 30, 2015

DOI http://dx.doi.org/10.4238/2015.November.30.17

\begin{abstract}
Heterosis has greatly contributed to conventional plant breeding and is widely used to increase crop plant productivity. However, although some studies have explored the mechanisms of heterosis at the genomic and transcriptome level, these mechanisms still remain unclear. The growth and development of maize seedlings and immature embryos have an important impact on subsequent production. This study investigated differentially expressed genes (DEGs) between parents and reciprocal hybrids in the seedling leaves, roots, and immature embryo 15 days after pollination using amplified fragment length polymorphism (AFLP)-based transcript profiling (cDNA-AFLP). We isolated 180, 170, and 108 genes from the leaves, roots, and immature embryos, respectively, that were differentially expressed between hybrids and parents. Sequencing and functional analysis revealed that 107 transcriptderived fragments in the roots and leaves and 90 in the immature embryos were involved in known functions, whereas many DEGs had roles in plant growth and development, photosynthesis, signal transduction, and seed germination. Quantitative reverse-transcription polymerase chain reaction analysis of relative expression levels between reciprocal hybrids and both parental genotypes of selected genes produced results that
\end{abstract}


were consistent with cDNA-AFLP. We validated the expression patterns of 15 selected genes related to heterosis formation and revealed that most showed non-additive expression in one or both hybrids, including dominant, underdominant, and overdominant expression. This indicates that gene-regulatory interactions among parental alleles play an important role in heterosis during the early developmental stages of maize.

Key words: cDNA-AFLP; Heterosis; Transcriptome level; Zea mays; Non-additive gene expression

\section{INTRODUCTION}

Heterosis is commonly used to describe the superior performance of heterozygous $\mathrm{F}_{1}$ hybrid plants relative to their homozygous parental inbred lines for a wide range of traits, including growth rate, yield, quality, and resistance to biotic and abiotic stress. Three classical quantitative genetic models have been proposed to describe the basis of heterosis. The first is the dominance hypothesis, which attributes heterosis to the complementation of slightly deleterious recessive alleles from the two inbred parents (Davenport, 1908; Bruce, 1910; Keeble and Pellew, 1910; Jones, 1917). The second is the overdominance hypothesis, in which heterotic traits occur through interactions of favorable alleles at one or more loci (Shull, 1908; East, 1936; Crow, 1948). The third is the epistasis hypothesis, which states that heterosis is the epistatic interaction of beneficial non-allelic genes at two or more loci in hybrids (Stuber, 1994; Goodnight, 1999). Although heterosis has been used by plant breeders for many years to develop crosses with improved agronomic characteristics, the complexity of its genetic basis and limitations of research methods mean that its molecular mechanisms remain largely unknown (Duvick, 1997).

Recent biotechnological developments have enabled quantitative trait loci positioning and high-throughput sequencing to analyze the mechanisms of heterosis. At the transcriptome level, differentially expressed genes (DEGs) have been identified between maize hybrids (Romagnoli et al., 1990; Tsaftaris and Polidoros, 1993; Tsaftaris and Kafka, 1998), whereas overexpressed genes were shown to play important roles in wheat heterosis (Sun et al., 1999; Ni et al., 2000). Meyer et al. (2007) speculated that heterosis in maize embryos is related to signal transduction as well as other regulatory processes and suggested that embryonic development after pollination has an important role in heterosis. Similarly, Wu et al. (2003) and Yao et al. (2005) detected differentially expressed transcription factors in the leaves and roots of wheat hybrids, indicating that heterosis is associated with genes related to signal transduction and other regulative processes. Using cDNA-amplified fragment length polymorphism (AFLP), Wu et al. (2001b) found that heterosis in maize hybrids results from the inhibition of genes inherited from both parent. We speculate that differential gene expression at different stages might lead to heterosis formation.

Maize growth primarily occurs during the seedling stage, and most reproductive growth occurs in the immature embryo during the first 15 days after pollination. At those stages, the seeding leaves and roots directly affect the nutrient supply, and the immature embryo after 15 days of pollination has considerable influence on ear and tassel development. Therefore, studies on the genetic mechanism of the five-leaf stage of maize and the immature embryo after pollination to improve efficiency of nutrient utilization have important implications in subsequent maize reproductive growth. 
The present study used cDNA-AFLP to analyze heterotic traits in maize during early development and identified candidate genes that are differentially expressed in hybrids compared with inbred parents. Quantitative reverse-transcription polymerase chain reaction (RT-PCR) analysis was applied to reveal relative expression levels between reciprocal hybrids and both parental genotypes of selected genes with the aim of better understanding the molecular mechanism of heterosis.

\section{MATERIAL AND METHODS}

\section{Maize materials and growth conditions}

The two maize inbred lines, YM251 ( + ) and YP125 ( $\left.{ }^{\Uparrow}\right)$, and its reciprocal hybrid $\left(\mathrm{F}_{1}^{+}\right.$ and $\mathrm{F}_{1}^{-}$) were selected for this study, and $\mathrm{F}_{1}^{+}$is a new variety of maize independently cultivated by our laboratory. Relative to the two parent lines, $\mathrm{F}_{1}{ }^{+}$has strong heterosis, including bigger ears, high quality, and strong resistance to abiotic stresses. All of the plants were grown in our laboratory with a 16-h light/dark period $(25 \mathrm{klux})$ at $25^{\circ} / 20^{\circ} \mathrm{C}$. Three biological replicates of each genotype were planted. When they entered the five-leaf stage, various morphological indexes were measured. The immature embryo 15 days after pollination was obtained from experimental plots.

\section{Total RNA extraction}

All materials were collected randomly from three seedlings for total RNA extractions using the RNAiso reagent (TaKaRa, Japan). RNAiso reagent was used to dissolve $50 \mathrm{mg}$ of each fresh sample, which was then centrifuged at $12,000 \mathrm{rpm}$ for $15 \mathrm{~min}$ at $4^{\circ} \mathrm{C}$. Then, the sample was mixed with $0.4 \mathrm{~mL}$ chloroform in the supernatant; after centrifugation at 12,000 rpm for 10 $\min$ at $4^{\circ} \mathrm{C}$, the upper layer of the solution was transferred into a new RNase-free 1.5 -mL tube in which there was $1 \mathrm{~mL}$ dehydrated alcohol. Then, the sample was centrifuged at $12,000 \mathrm{rpm}$ for 15 min at $4^{\circ} \mathrm{C}$ again. The pellet was dissolved in $20 \mathrm{~mL}$ RNase-free double-distilled water $\left(\mathrm{ddH}_{2} \mathrm{O}\right)$. To prevent the influence of DNA on the follow-up experiments, DNaseI (deoxyribonucleic acid enzyme I) was used to remove the genomic DNA. Quality and quantity of purified RNA was checked by agarose gel electrophoresis and spectrophotometer, respectively.

\section{Double-strand cDNA synthesis}

First-strand cDNA and double-strand cDNA were synthesized according to the protocols described by Manickavelu et al. (2007). Some steps were modified as necessary. The first-strand cDNA synthesis reaction included $1.5 \mu \mathrm{g}$ total RNA, $2 \mu \mathrm{L}$ oligo (dT) 18 primer $(50 \mu \mathrm{M}), 1 \mu \mathrm{L}$ M-MLV (Moloney Murine Leukemia Virus) reverse transcriptase (200 U/ $\mu \mathrm{L})$, $4 \mu \mathrm{L} 5 \mathrm{X}$ M-MLV buffer, $4 \mu \mathrm{L}$ dNTPs $(2.5 \mathrm{mM}$ each), and $0.5 \mu \mathrm{L}$ RNase inhibitor (40 U/ $\mu \mathrm{L})$; sometimes, $\mathrm{RNase}$-free $\mathrm{ddH}_{2} \mathrm{O}$ was added to make the mixture $20 \mu \mathrm{L}$. These mixed solutions were incubated at $42^{\circ} \mathrm{C}$ for $1 \mathrm{~h}$, then $70^{\circ} \mathrm{C}$ for $15 \mathrm{~min}$, and then immediately placed on ice for 2 $\mathrm{min}$. The $30-\mu \mathrm{L}$ second-strand cDNA synthesis reaction mixture consisted of $10 \mu \mathrm{L}$ first-strand cDNA, $3 \mu \mathrm{L} 10 \mathrm{X} \mathrm{T}_{4}$ Ligase buffer, $0.5 \mu \mathrm{L} \mathrm{T}_{4}$ Ligase (350 U/ $\left.\mu \mathrm{L}\right), 0.5 \mu \mathrm{L}$ RNase $\mathrm{H}(60 \mathrm{U} / \mu \mathrm{L})$, $3 \mu \mathrm{L} 10 \mathrm{X}$ DNA Polymerase I buffer, $2 \mu \mathrm{L}$ DNA Polymerase I $(4 \mathrm{U} / \mu \mathrm{L})$ and $6 \mu \mathrm{L}$ dNTPs $(2.5$ $\mathrm{mM}$ each) and some $\mathrm{ddH}_{2} \mathrm{O}$. The above mixture was incubated at $16^{\circ} \mathrm{C}$ for $150 \mathrm{~min}, 80^{\circ} \mathrm{C}$ for $10 \mathrm{~min}$ and then was immediately frozen for $2 \mathrm{~min}$. 


\section{cDNA-AFLP analysis}

As described by Vos et al. (1995), the cDNA-AFLP analysis was performed with slight modifications. First, the double-strand cDNA was completely digested at $37^{\circ} \mathrm{C}$ with $M s e \mathrm{I} / \mathrm{PstI}_{\mathrm{I}}$ and $M s e \mathrm{I} / E c o \mathrm{RI}$; then, all appropriate adaptors were used in a coupled reaction. $M 0, P 0$, and $E 0$ were designed according to each adaptor and were used as pre-amplification primers. Ten $M$ seI selective primers $(M 1, M 2, M 3, M 4, M 5, M 6, M 7, M 8, M 9$, and $M 10), 16 P$ st I selective primers ( $P 1, P 2, P 3, P 4, P 5, P 6, P 7, P 8, P 9, P 10, P 11, P 12, P 13, P 14, P 15$, and $P 16)$, and eight $E c o$ RI selective primers (E1,E2,E3,E4,E5,E6, E7, and $E 8)$ were used for selective amplification. The above mentioned sequences are listed in Table S1. Each ligated sample was diluted 10 -fold with $\mathrm{ddH}_{2} \mathrm{O}$, and $5 \mu \mathrm{L}$ of each sample was used for pre-amplification reactions. The PCR conditions were as follows: $94^{\circ} \mathrm{C}$ for $30 \mathrm{~s}, 56^{\circ} \mathrm{C}$ for $1 \mathrm{~min}$, and $72^{\circ} \mathrm{C}$ for $1 \mathrm{~min}$ for 25 cycles. The production of each pre-amplification reaction was diluted 20 -fold with $\mathrm{ddH}_{2} \mathrm{O} ; 5$ $\mu \mathrm{L}$ of each sample was used for the selective amplification reactions, and the PCR conditions were: $94^{\circ} \mathrm{C}$ for $3 \mathrm{~min} ; 94^{\circ} \mathrm{C}$ for $30 \mathrm{~s}, 65^{\circ} \mathrm{C}$ for $1 \mathrm{~min}\left(-0.7^{\circ} \mathrm{C}\right.$ per cycle), and $72^{\circ} \mathrm{C}$ for $1 \mathrm{~min}$ for 12 cycles; followed by $94^{\circ} \mathrm{C}$ for $30 \mathrm{~s}, 56^{\circ} \mathrm{C}$ for $1 \mathrm{~min}$, and $72^{\circ} \mathrm{C}$ for $1 \mathrm{~min}$ for 23 cycles, then $4^{\circ} \mathrm{C}$ thereafter. Selective amplification products were denatured at $94^{\circ} \mathrm{C}$, separated using a $4.5 \%$ polyacrylamide gel, and visualized by silver staining about $2.5 \mathrm{~h}$ later.

\section{Isolating and sequencing transcript-derived fragments (TDFs)}

Fragments with molecular weights of 100-600 bp were used for statistical analysis. Depending on whether a fragment could be detected among the $F_{1}$ and its two parents, the differentially expressed genes were isolated from the gel that was rehydrated in $30 \mu \mathrm{L}$ water after it was incubated at $37^{\circ} \mathrm{C}$ for $8 \mathrm{~h}$ and $94^{\circ} \mathrm{C}$ for $20 \mathrm{~min}$. The TDFs were then re-amplified using PCR under the same conditions and with the same primers used for the selective amplification, recovered the PCR products from agarose gel electrophoresis, and cloned into a pUC-T cloning vector. Then, after transformation into Escherichia coli (strain DH5a) after 12 $\mathrm{h}$ of culture at $37^{\circ} \mathrm{C}$, the transformed bacteria were plated onto LB agar plates that contained ampicillin; finally, the white colonies in the LB broth, identified by PCR, and the positive clones were sequenced by the BGI Company (China).

\section{Sequence analysis}

A vector sequence that was trimmed around the plasmid was used as the template in the DNAman software; homology with nucleotides was analyzed using the MaizeGDB (http:// www.maizegdb.org/blast.php) BLAST or NCBI database (http://www.ncbi.nlm.nih.gov/) using the BLASTn algorithms. The functions of the function-known genes were classified according to Blast2GO or agriGO.

\section{qRT-PCR analysis}

Real-time RT-PCR (qRT-PCR) experiments were carried out using an ABI 7500 Real-Time PCR System and the 7500 System version 2.0.5 software. RNA extraction was performed according as described above. First-strand cDNAs were synthesized using a PrimeScript RT Reagent Kit with gDNA Eraser (TaKaRa, China). The qRT-PCR candidate 
genes were selected based on TDFs that were differential expressed between two hybrids and their parents, and the specific primer pairs were designed with the Primer Premier 5 software. Three independent samples were used in these experiments, and all reactions were run in triplicate. The constitutively expressed genes actin, GAPDH, and tubulin were used as internal controls for normalization. According to the manufacturer instructions, all PCRs were mixed as follows: $2 \mu \mathrm{L}$ cDNA (diluted 5-fold with $\mathrm{ddH}_{2} \mathrm{O}$ ), $10 \mu \mathrm{L} 2 \mathrm{X}$ SYBR Premix Ex Taq II (TaKaRa, China), $0.4 \mu \mathrm{L}$ 50X ROX Reference Dye II, $0.4 \mu \mathrm{L}$ of each primer, and $\mathrm{ddH}_{2} \mathrm{O}$ to produce a final volume of $20 \mu \mathrm{L}$ PCR. All qRT-PCRs were conducted under the following conditions: $95^{\circ} \mathrm{C}$ for $30 \mathrm{~s} ; 95^{\circ} \mathrm{C}$ for $5 \mathrm{~s}, 60^{\circ} \mathrm{C}$ for $30 \mathrm{~s}$, and $72^{\circ} \mathrm{C}$ for $30 \mathrm{~s}$ for 40 cycles. Reactions that displayed deviant melting curves were excluded from further analysis.

\section{RESULTS}

\section{Heterosis influences early morphological traits after maize germination}

To analyze the manifestation of heterosis during the seedling stage, we compared the morphological traits of hybrid and inbred maize plants at the five-leaf stage (Figure S1). To ensure identical growth conditions, both inbred and reciprocal hybrid genotype seeds were sown under equal amounts of sand and irrigated with identical quantities of nutrient solution. Measurement of the aboveground fresh weight and dry weight, underground fresh weight and dry weight, root length, and leaf area of three randomly selected plants of four different maize genotypes at the five-leaf stage reported higher values for all characteristics in both reciprocal hybrids compared with inbred plants (Figure 1). This indicates that heterosis in maize is apparent at the seedling stage and that the morphological traits of hybrid $\mathrm{F}_{1}{ }^{-}$are better than those of hybrid $\mathrm{F}_{1}^{+}$. Thus, hybrids developed from such inbred plants would be expected to exhibit morphologic heterosis but not yield heterosis.
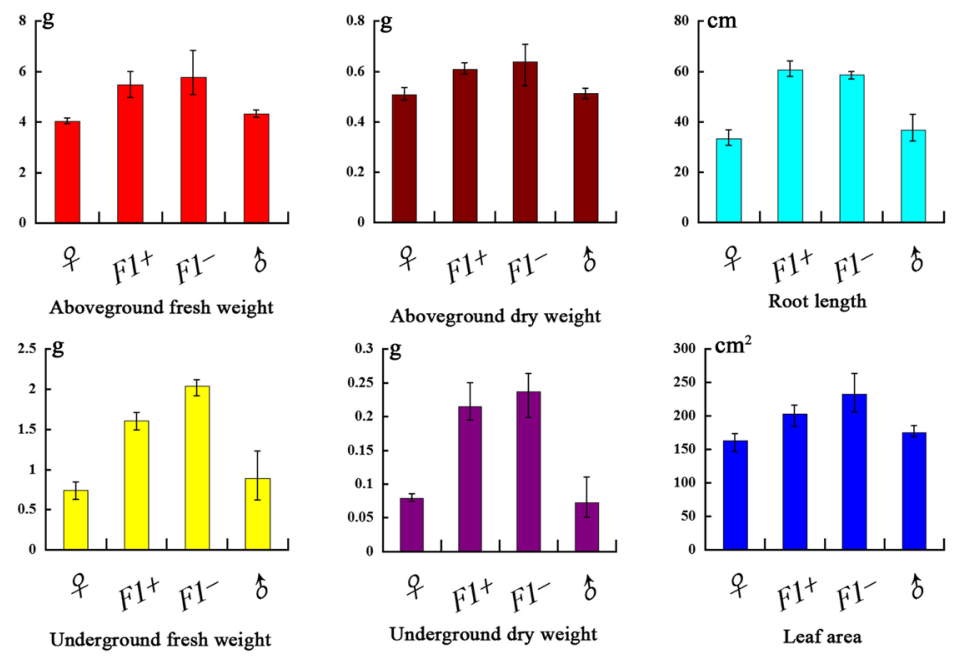

Figure 1. Heterosis at the five-leaf stage of maize. Histograms represent the data of six morphological traits: aboveground fresh weight, aboveground dry weight, root length, underground fresh weight, underground dry weight, and leaf area of the four genotypes. Error bars represent standard error. 


\section{Identification of DEGs between hybrid and inbred maize}

cDNA-AFLP was used to identify candidate genes associated with maize heterosis that were differentially expressed in the leaves and roots at the seedling stage and in the immature embryo (15 days post-pollination) between two maize inbred lines (YM251 and YP125) and the reciprocal hybrids (YM251 x YP125 and YP125 x YM251). Two hundred and forty primer combinations were used in cDNA-AFLP analysis, including $160 \mathrm{Mse} / \mathrm{PstI}(10 \mathrm{x} \mathrm{16)}$ and $80 \mathrm{Mse} /$ EcoRI (10 x 8) primer combinations. Approximately 15,000 TDFs were displayed, of which around 6500 were from the roots, and the remainder were from the leaves and the immature embryos (Figure 2). Based on the presence or absence of TDFs (qualitative variants) and differences in intensity (quantitative variants) between the four genotypes, a total of 458 differential TDFs were excised from silver-stained cDNA-AFLP gels. Most (90\%) of these variants were qualitative, and 10\% were quantitative. Re-amplification of these differential TDFs using the original selective primers was successful for 432, with sequences ranging from 100 to $600 \mathrm{bp}$ (mean, $300 \mathrm{bp}$ ). Of these clones, 156 sequences were isolated from the leaves, 174 sequences from the roots, and 102 sequences from the immature embryos.

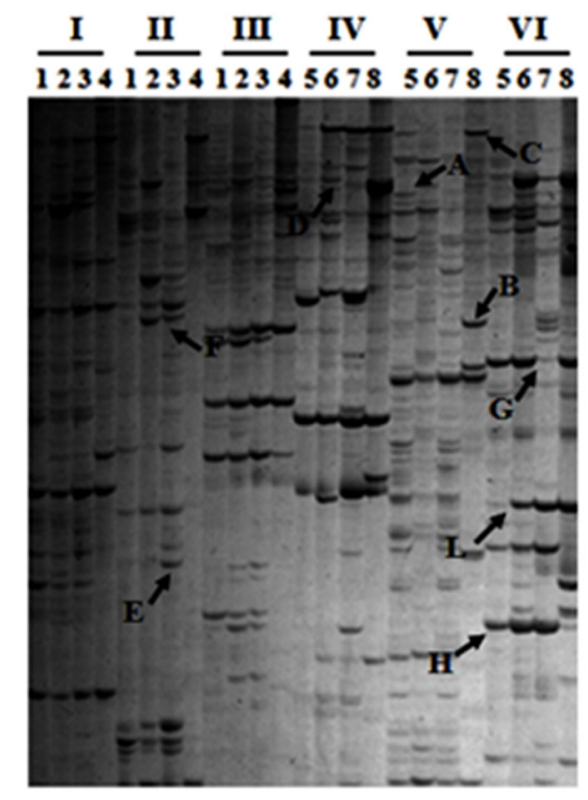

a

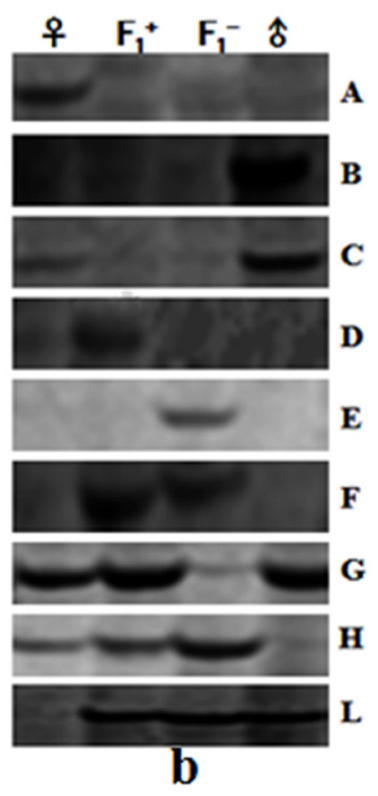

Figure 2. a. Silver-stained cDNA-AFLP gel showing genes differentially expressed in the leaves, roots, and immature embryos between two maize inbred lines and the reciprocal hybrid. Lane $1=\mathrm{YM} 251$ ( $(+)$ leaf; lane $2=$

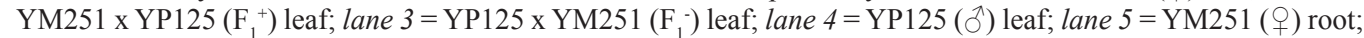
lane $6=\mathrm{YM} 251 \times \mathrm{YP} 125\left(\mathrm{~F}_{1}^{+}\right)$root; lane $7=\mathrm{YP} 125 \times \mathrm{YM} 251\left(\mathrm{~F}_{1}^{-}\right)$root; and lane $8=\mathrm{YP} 125\left(\delta^{-}\right)$root. The gel of the immature embryo is not shown. Each group was amplified with a different pair of selective AFLP primers: I, M1/E1; II, M1/E2; III, M1/E3; IV, M7/P1; V, M7/P2; or VI, M7/P3. b. Patterns of differential expression between hybrids and their parents. A: Bands expressed only in maternal parent; B: bands expressed only in paternal parent; $\mathrm{C}$ : bands expressed only in two parents; D: bands expressed only in $\mathrm{F}_{1}^{+}$; $\mathrm{E}$ : bands expressed only in $\mathrm{F}_{1}$; F: bands expressed in $\mathrm{F}_{1}$ but not in two parents; $\mathrm{G}$ : bands expressed in both parents and $\mathrm{F}_{1}^{+}$; $\mathrm{H}$ : bands expressed in maternal parent and two hybrids; and L: bands expressed in paternal parent and two hybrids. 
Sequence comparisons with MaizeGDB (http://www.maizegdb.org/blast.php) revealed that 132 genes from the 156 leaf clones, together with 116 from the 174 root clones, and 90 from the 102 immature embryo clones were homologous to those in the database. Most of these genes demonstrated higher expression levels in the hybrids compared with parental lines. Twenty-four genes encoded proteins with unknown functions, whereas some high-homology sequences of the other 314 TDFs represented the same candidate gene. For example, TDFs Y-8 (482 bp) and Y-16 (446 bp) both encoded an RNA-binding (RRM/RBD/RNP motifs) family protein but were identified from the different selective primer combinations of M10/P6 and M10/P11, whereas G-124 (347 bp) and G-99 (235 bp) both represent an $\mathrm{E}_{2} \mathrm{~F}$ target gene but were cloned from the different primer combinations of M5/P1 and M7/P2.

\section{Functional classification of candidate genes}

BLAST analysis using the MaizeGDB database identified 107 TDFs with functions in the root between the two maize inbred lines and their reciprocal hybrids. All TDF sequences were functionally annotated using Blast2GO, most of which were assigned to the three main categories of biological process, molecular function, and cellular complement. TDFs representing genes involved in biological processes mainly participated in cellular macromolecule metabolism (16\%), nucleobase-containing compound metabolism (15\%), protein metabolism (14\%), macromolecule biosynthesis $(7 \%)$, macromolecule modification $(5 \%)$, heterocycle biosynthesis $(4 \%)$, and signal transduction $(2 \%)$; a number of genes participated in other biological processes $(29 \%)$. For molecular function, most TDFs had roles in the binding of heterocyclic compounds (24\%), organic cyclic compounds (24\%), and small molecules (14\%). Other relevant TDF categories included transferase activity, hydrolase activity, protein binding, sequence-specific DNA binding transcription factor activity, signal transducer activity, lipid binding, and chromatin binding. For TDFs grouped by cellular components, $31 \%$ were associated with the nucleus and $16 \%$ with plastids. Residual TDFs were assigned to intracellular organelle lumens, cytosols, microbodies, the endoplasmic reticulum, Golgi apparatus, vacuoles, and other cellular components (Figure 3A).

Using the same technique, we showed that the 107 leaf TDFs were more enriched for genes involved in the regulation of cellular protein metabolic processes, heterocyclic compound binding, hydrolase activity, regulation of nucleic acid metabolic processes, and protein modification. They also included some genes participating in the regulation of gene expression, reproductive system development, and shoot system development. Some genes encoded important parts of plant cellular components such as plastids, mitochondria, nuclei, and ribosomes. Detailed findings are shown in Figure 3B and indicate that different maize genotypes have DEGs of varying functions during the early stage of leaf development.

Through BLAST analysis using the agriGO database, the 90 immature embryo TDFs were divided into categories according to their functions. Binding proteins and proteins participating in metabolic processes accounted for the largest proportion, while other encoded proteins participated in cellular processes, compartmentalization, catalytic activities, biological regulation, transporter activity, and localization (Figure 3C). Among the functional sequences, the inclusion of proteins such as DHHC-type zinc finger family protein and serine carboxypeptidase-like 33 indicate that their association with heterosis may be through increases in seed size and weight by different metabolic pathways. 
A

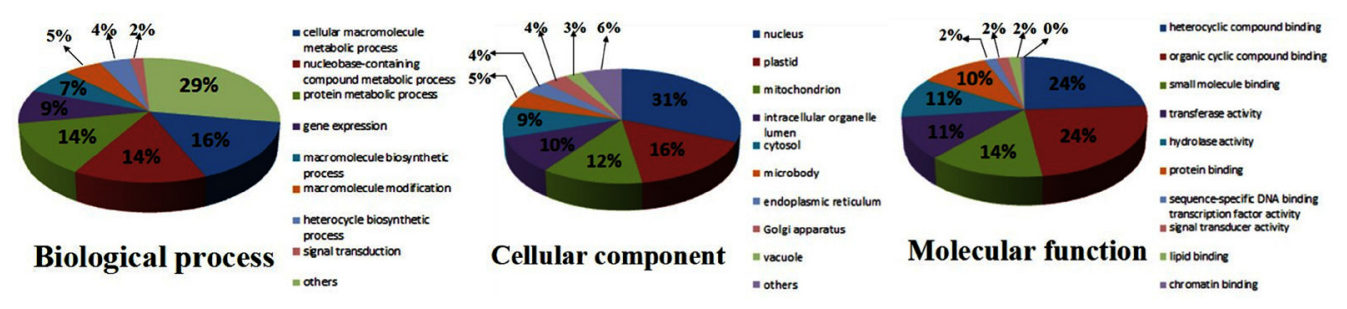

\section{B}
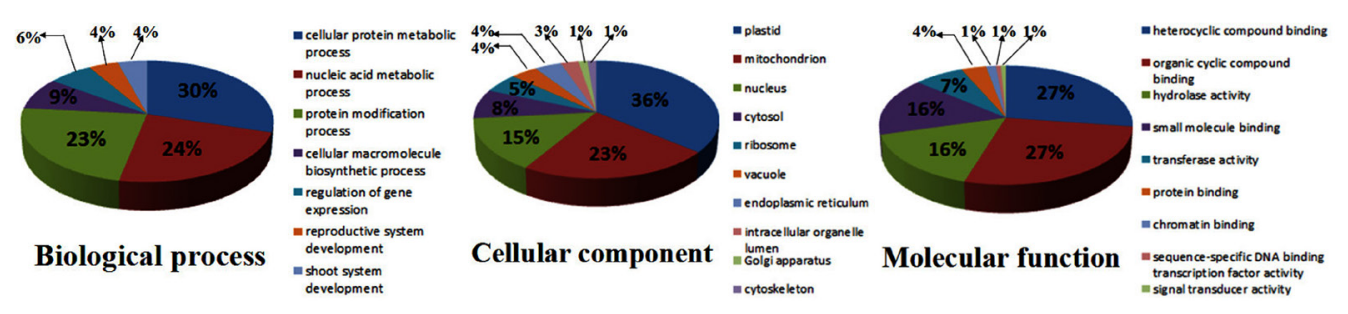

C

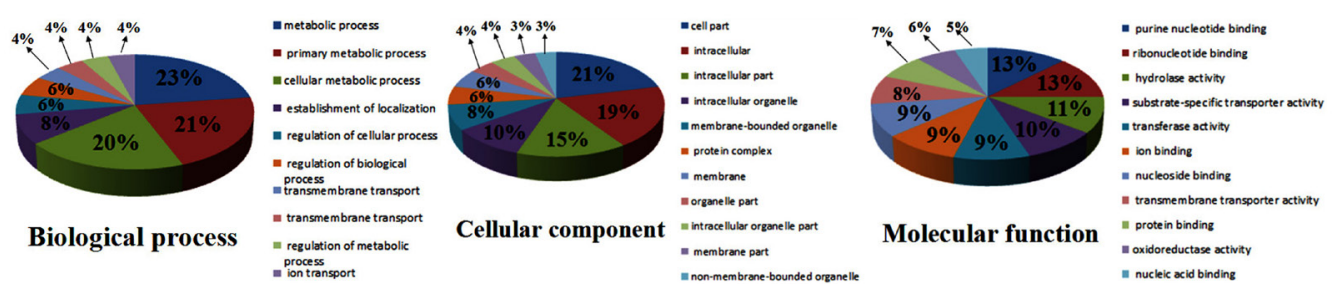

Figure 3. Classification of differentially expressed genes between hybrids and parental genotypes. Functional classifications were based on Blast2GO for the three main gene ontology categories: molecular function, cellular component, and biological process. A. Transcript-derived fragments (TDFs) from roots; B. TDFs from leaves; and C. TDFs from immature embryos.

\section{Validation of functional DEGs by real-time qRT-PCR}

To validate the cDNA-AFLP results, we next carried out qRT-PCR of 15 genes that were differentially expressed between two inbred lines and reciprocal hybrids (Table 1). Five of these genes (Y-14, Y-65, Y-86, Y-94, and Y-139) were expressed in the leaves and involved in plant growth and development, photosynthesis, nutrient absorption, and ATP synthesis. Another five were selected from the root (G-74, G-81, G-96, G-125, and G-175) and showed homology with stress-responsive proteins, root hair growth-promoting proteins, and RNA or DNA-binding proteins. The final five from the immature embryo (P-2, P-3, P-6, $\mathrm{P}-15$, and P-66) encoded proteins such as DHHC-type zinc finger family protein, RING/Ubox superfamily protein, serine carboxypeptidase-like 33, transducin family protein/WD40 repeat family protein, and dehydration-induced protein (ERD15), which are involved in seed development and adversity resistance. All of the 15 genes could be associated with the formation of heterosis at different stages of maize development. The expression patterns of 
most candidate genes were similar to those observed by cDNA-AFLP, indicating the reliability of that technique. With the exception of Y-14, which showed expression differences between qRT-PCR and cDNA-AFLP data, the remaining genes were candidates for further molecular analyses of heterosis-related gene expression in the maize seedling stage and reproductive period (Figure 4).

Table 1. qRT-PCR candidate genes.

\begin{tabular}{|c|c|c|c|c|c|}
\hline TDF & Length (bp) & Primer combination & Accession No. & Sequence similarity & E-value \\
\hline Y-14 & 324 & $\mathrm{M} 10 / \mathrm{P} 10$ & GRMZM2G001180_T02 & F-box/RNI-like superfamily protein & $2.664 \mathrm{e}-54$ \\
\hline Y-65 & 178 & M9/P2 & GRMZM2G012397_T01 & Photosystem I subunit K & $5.06 \mathrm{e}-08$ \\
\hline Y-86 & 409 & M7/P5 & GRMZM2G319781_T01 & Phosphatidylinositol transfer protein alpha isoform & $7.060 \mathrm{e}-18$ \\
\hline Y-94 & 255 & $\mathrm{M} 7 / \mathrm{P} 8$ & GRMZM5G855347_T02 & P-type ATPase of Arabidopsis 2 & $8.03 \mathrm{e}-85$ \\
\hline Y-139 & 253 & M6/P1 & GRMZM2G099045-T01 & ATP binding cassette protein 1 & $2.193 \mathrm{e}-32$ \\
\hline G-74 & 436 & $\mathrm{M} 8 / \mathrm{P} 13$ & GRMZM2G150248_T01 & Polyamine oxidase 4 & $6.688 \mathrm{e}-76$ \\
\hline G-81 & 361 & $\mathrm{M} 8 / \mathrm{P} 15$ & GRMZM2G079817_T01 & RAN GTPase activating protein 1 & $6.906 e-58$ \\
\hline G-96 & 305 & $\mathrm{M} 7 / \mathrm{P} 2$ & GRMZM5G886952_T01 & Leucine-rich repeat protein kinase family protein & $3.871 \mathrm{e}-45$ \\
\hline G-125 & 278 & $\mathrm{M} 3 / \mathrm{E} 1$ & GRMZM2G704053_T02 & Sec14p-like phosphatidylinositol transfer family protein & $1.116 \mathrm{e}-44$ \\
\hline G-175 & 304 & M5/P14 & GRMZM2G053868_T01 & Calcium-dependent protein kinase 16 & $2.983 \mathrm{e}-45$ \\
\hline P-2 & 311 & M6/E3 & GRMZM2G111191_T01 & DHHC-type zinc finger family protein & $6.30 \mathrm{E}-51$ \\
\hline P-3 & 338 & $\mathrm{M} 6 / \mathrm{E} 3$ & GRMZM2G174926 T01 & RING/U-box superfamily protein & $5.74 \mathrm{E}-57$ \\
\hline P-6 & 315 & $\mathrm{M} 8 / \mathrm{E} 1$ & GRMZM2G123815_T01 & Serine carboxypeptidase-like 33 & $1.49 \mathrm{E}-52$ \\
\hline P-15 & 368 & M8/E5 & GRMZM2G007021_T01 & $\begin{array}{l}\text { Transducin family protein/WD- } 40 \text { repeat } \\
\text { family protein }\end{array}$ & $1.115 \mathrm{e}-60$ \\
\hline P-66 & 259 & $\mathrm{M} 2 / \mathrm{P} 6$ & GRMZM5G845782_T01 & Dehydration-induced protein (ERD15) & $2.944 \mathrm{e}-24$ \\
\hline
\end{tabular}
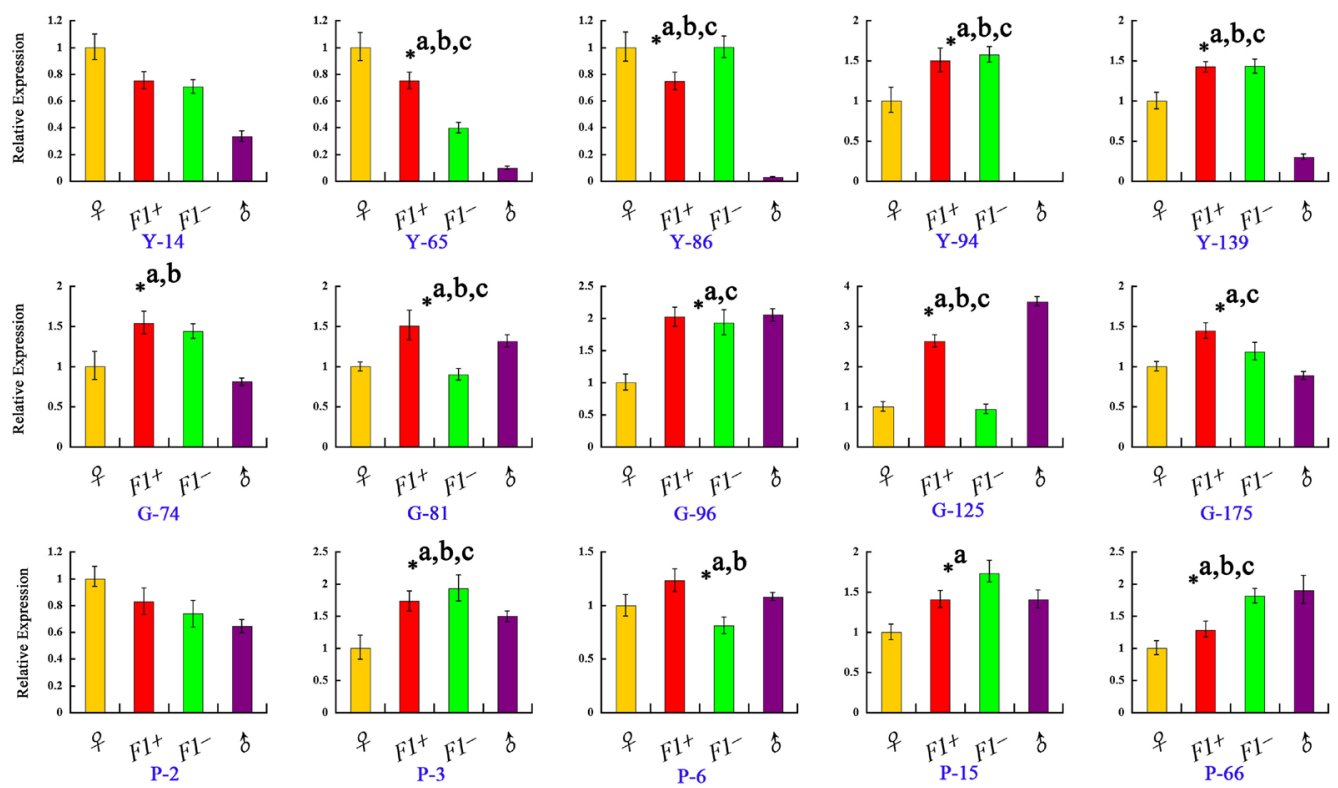

Figure 4. qRT-PCR analysis of relative gene expression levels between two parental lines and the reciprocal hybrid in roots, leaves, and embryos. Mean values and standard deviations of data were normalized to those of actin, GAPDH, and tubulin. Significance is indicated for $\left({ }_{*}^{a}, \mathrm{P} \leq 0.05\right)$ validation of the expression between $O$ and $\mathrm{F}_{1}^{+}$or (and) $\mathrm{F}_{1} ;{ }_{*} ;{ }_{*}^{\mathrm{b}}$, $\mathrm{P} \leq 0.05)$ the expression between $\delta^{\lambda}$ and $\mathrm{F}_{1}^{+}$or $($and $) \mathrm{F}_{1} ;$; and $\left({ }_{*}^{c}, \mathrm{P} \leq 0.05\right)$ the expression between ${ }_{+}$and $\partial^{-}$. 


\section{qRT-PCR revealed diverse expression patterns among both reciprocal hybrids and parental inbred lines}

Based on our statistical analysis, gene expression patterns could be sorted into two categories: additive (levels of hybrid transcripts equal to those of the mid-parent) and nonadditive (levels of hybrid transcripts not equal to those of the mid-parent) (Wu et al., 2003). We investigated relative expression levels of 15 selected genes among the four genotypes using qRT-PCR. Most of these genes were shown to have non-additive expression patterns, in which the expression level of one or both hybrids deviated significantly from the mid-parent value or the level of the higher parental line. As shown in Figure 4, only three genes showed additive expression (G-125, P-2, and P-66); P-2 expression did not significantly deviate from the mid-parental value in either hybrid, whereas G-125 and P-66 expression did not significantly deviate from the mid-parental value in only one hybrid. The behavior of 10 genes (Y-86, Y-94, Y-139, G-74, G-81, G-96, G-175, P-3, P-6, and P-15) was dominant, with a significantly (P $\leq$ 0.05 ) higher or lower expression observed in the hybrids than the mid-parental level. All genes showed higher expression in both reciprocal hybrids than the mid-parental value, except for G-81 and P-6, which demonstrated lower expression in $\mathrm{F}_{1}{ }^{-}$than the mid-parental value. In the male parent inbred line YP125 genotype, Y-94 gene expression was below the detection limit, whereas Y-86 transcripts were only detected at a low level in one biological replicate. Gene Y-65 showed dominant expression in one hybrid relative to one parental line. At a significance level of P $\leq 0.05$, eight genes (G-81, G-125, P-3, P-66, Y-65, Y-86, Y-94, and Y-139) exhibited dominance in one hybrid compared with the parent and also exhibited a significant difference in expression $\left({ }_{*}^{c}, \mathrm{P} \leq 0.05\right)$ between the two parental lines.

\section{DISCUSSION}

Heterosis refers to the phenomenon that $\mathrm{F}_{1}$ hybrids exceed parental inbred lines with respect to biomass, size, yield, speed of development, fertility, and resistance to biotic and abiotic stresses. Although $\mathrm{F}_{1}$ hybrids are widely used in agriculture, the underlying molecular mechanisms of this phenomenon remain largely elusive. Recently, DEG studies between hybrids and their parental lines mainly focused on different maize organs and developmental stages, including immature ears (Guo et al., 2006; Stupar and Springer, 2006) and endosperm (Guo et al., 2003; Song and Messing, 2003), embryos (Stupar and Springer, 2006; Meyer et al., 2007), adult leaves (Auger et al., 2005), shoot apical meristems (Uzarowska et al., 2007), and whole seedlings (Stupar and Springer., 2006; Swanson-Wagner et al., 2006). Other investigations focused on the transcriptomes of Arabidopsis leaves (Vuylsteke et al., 2005) and rice panicles (Huang et al., 2006). Although maize leaves and roots at the five-leaf stage lay the foundation for future growth, provide nutrients for the entire growth cycle, and the immature embryo influences seed quality and germination, very little is known about how gene expression variation is related to heterosis. In our study, we showed that heterotic traits in hybrid roots and leaves of maize are established at the five-leaf stage and investigated the DEG expression patterns between hybrids and parental lines.

Previously, hybrid maize seedlings were shown to display heterotic traits immediately after germination. For example, heterosis was observed in young primary roots 3.5 days after germination by comparing morphological traits of reciprocal hybrids and parental genotypes 
(Hoecker et al., 2006, 2008). In the present study, we showed that $F_{1}$ hybrids exhibited heterosis during the five-leaf stage after confirming that these dates of measurement were sufficiently stable to allow the accurate determination of values for all three biological replicates.

We applied cDNA-AFLP to identify DEGs between hybrid and parental genotypes. This experimental technology was previously shown to have high reproducibility and reliability and the ability to identify genes from different lengths of cDNA restriction fragments; therefore, it seemed suitable to analyze the expression of genes of interest in our present study (Maria and Fouad, 2010; Song et al., 2012). We identified several DEGs among the four genotypes, of which some showed differences in expression between hybrids and parents. Because all genes of a hybrid are derived from its parents, any quantitative or qualitative differences in gene expression are likely to reflect phenotypic variations (Tian and Dai, 2003). However, heterosis in maize and wheat was also suggested to be associated with the inhibition of genes inherited from both parents (Wu et al., 2001a,b). Therefore, we analyzed differentially expressed fragments, including $\mathrm{F}_{1}-$ specific expressed fragments, dominant fragments from one parent, fragments observed only in both parents, and fragments detected in only one parent.

We successfully recovered 432 DEGs in the roots, leaves, and immature embryos of maize, of which 338 showed homology to known sequences. Many of these genes are involved in metabolic and cellular processes; binding to RNA, protein, or DNA; or acting as co-factors or components of small GTPase-mediated signal transduction pathways. This indicates that epistatic effects are associated with heterosis formation. We also observed a significant enrichment of sequences that were homologous to genes involved in biotic and abiotic stimulus responses, especially in the roots and immature embryos. These genes have the potential to contribute to vigorous plant development, which may play a key role in the formation of heterosis. Additionally, a large number of unknown sequences were identified that did not show homology to any known open reading frame (ORF). Although they might represent previously unidentified ORFs, they most probably derived from 5'- or 3'-noncoding sequences. The future exploration of these unknown sequences could improve our understanding of the molecular mechanisms of maize heterosis.

Additive and non-additive gene expression patterns were previously proposed to explain heterosis at the molecular level (Wu et al., 2003). Further recent comparisons of heterosis-associated gene expression patterns showed that non-additive gene expression was sometimes prevalent between inbred lines and hybrids and may play an important role in heterosis formation (Hochholdinger and Hoecker, 2007). However, other studies observed additive expression for most key genes (Melchinger, 1999). This discrepancy could be explained by the differences in genotypes, experimental design, and statistical procedures used in the various studies (Stupar and Springer, 2006; Swanson-Wagner et al., 2006; Meyer et al., 2007; Song et al., 2010). In the present study, we found that non-additive gene expression patterns were prevalent between the reciprocal hybrid and its parents, which is similar to the non-additive gene expression seen for $94.4 \%$ of DEGs during spikelet differentiation and $82 \%$ during floscule differentiation in DGhup (differentially expressed genes unique between the hybrid and its parents) between the hybrid Zhengdan 958 and its parents (Li et al., 2012). Moreover, approximately half of the genes previously analyzed between 16 maize hybrids and their respective inbred parents showed non-additive expression in immature ears, while non-additive gene expression was also found to prevail in the meristems of hybrids and parental inbred lines (Guo et al., 2006; Uzarowska et al., 2007). Studies on additive gene 
expression suggested that the additive expression pattern is consistent with the dominance hypothesis and might be controlled by cis-elements (Stupar and Springer, 2006; SwansonWagner et al., 2006). Conversely, studies on non-additive gene expression patterns speculated that these patterns are associated with trans-regulation or trans-acting factors (Hoecker et al., 2008). We found that some genes exhibited non-additive expression patterns in both reciprocal hybrids, most of which showed higher expression levels relative to the parents. Such genes appear to be involved in ion transport and stress resistance, which could contribute to heterosis development.

In summary, the analysis of gene expression during the five-leaf stage of maize roots and leaves and in immature embryos 15 days after pollination revealed multiple DEGs between parental inbred lines and reciprocal hybrids. Our findings indicate that non-additive gene expression patterns appear to contribute to a better understanding of heterosis. However, because heterosis formation is such a complex process, our research may have only partially elucidated its molecular and genetic mechanisms, so further studies are warranted.

\section{Conflicts of interest}

The authors declare no conflict of interest.

\section{ACKNOWLEDGMENTS}

Research supported by the National High Technology Research and Development Program of China ("863" Program; \#2011AA10A103) and the Science Development Planning of Jilin Province (\#20126030 and \#20140307027NY).

\section{Supplementary material}

\section{REFERENCES}

Auger DL, Gray AD, Ream TS, Kato A, et al. (2005). Nonadditive gene expression in diploid and triploid hybrids of maize. Genetics 169: 389-397.

Bruce AB (1910). The Mendelian theory of heredity and the augmentation of vigor. Science 32: 627-628.

Crow JF (1948). Alternative hypotheses of hybrid vigor. Genetics 33: 477-487.

Davenport CB (1908). Degeneration, albinism and inbreeding. Science 28: 454-455.

Duvick DN (1997). Heterosis: feeding people and protecting natural resources. In: The genetics and exploitation of heterosis in crops (Coors JG and Pandey S, eds.). American Society of Agronomy, Inc., Madison, 19-29.

East EM (1936). Heterosis. Genetics 21: 375-397.

Goodnight CJ (1999). Epistasis and heterosis. In: The genetics and exploitation of heterosis in crops (Coors JG and Pandey S, eds.). American Society of Agronomy, Inc., Madison, 59-67.

Guo M, Rupe MA, Danilevskaya ON, Yang X, et al. (2003). Genome-wide mRNA profiling reveals heterochronic allelic variation and a new imprinted gene in hybrid maize endosperm. Plant J. 36: 30-44.

Guo M, Rupe MA, Yang X, Crasta O, et al. (2006). Genome-wide transcript analysis of maize hybrids: allelic additive gene expression and yield heterosis. Theor. Appl. Genet. 113: 831-845.

Hochholdinger F and Hoecker N (2007). Towards the molecular basis of heterosis. Trends Plant Sci. 12: 427-432.

Hoecker N, Keller B, Piepho HP and Hochholdinger F (2006). Manifestation of heterosis during early maize (Zea mays L.) root development. Theor. Appl. Genet. 112: 421-429.

Hoecker N, Keller B, Muthreich N, Chollet D, et al. (2008). Comparison of maize (Zea mays L.) F1-hybrid and parental inbred line primary root transcriptomes suggests organ-specific patterns of non-additive gene expression and conserved expression trends. Genetics 179: 1275-1283. 
Huang Y, Zhang L, Zhang L, Yuan D, et al. (2006). Heterosis and polymorphisms of gene expression in an elite rice hybrid as revealed by a microarray analysis of 9198 unique ESTs. Plant Mol. Biol. 62: 579-591.

Jones DF (1917). Dominance of linked factors as a means of accounting for heterosis. Genetics 2: 466-479.

Keeble F and Pellew C (1910). The mode of inheritance of stature and of time of flowering in peas (Pisum sativum). J. Genet. 1: 47-56.

Li ZY, Zhang TF and Wang SC (2012). Transcriptomic analysis of the highly heterotic maize hybrid Zhengdan 958 and its parents during spikelet and floscule differentiation. J. Integr. Agr. 11: 1783-1793.

Manickavelu A, Kambara K, Mishina K and Koba T (2007). An efficient method for purifying high quality RNA from wheat pistils. Colloids Surf. B Biointerfaces 54: 254-258.

Maria AH and Fouad D (2010). Identification and cloning of differentially expressed genes involved in the interaction between potato and Phytophthora infestans using a subtractive hybridization and cDNA-AFLP combinational approach. J. Integr. Plant Biol. 52: 453-467.

Melchinger AE (1999). Genetic diversity and heterosis. International symposium on genetics and exploitation of heterosis in crop plants. Soil Science Society of America, Inc., Madison, 99-118.

Meyer S, Pospisil H and Scholten S (2007). Heterosis associated gene expression in maize embryos 6 days after fertilization exhibits additive, dominant and overdominant pattern. Plant Mol. Biol. 63: 381-391.

Ni ZF, Sun QX and Wu LM (2000). Differential gene expression between wheat hybrids and their parental inbreds in seedling leaves of early and vigorous tillering stage. J. China Agric. Univ. 5: 1-8.

Romagnoli S, Maddaloni M, Livini C and Moto M (1990). Relationship between gene expression and hybrid vigor in primary root tops of young maize (Zea may L.) plantlets. Theor. Appl. Genet. 80: 769-775.

Shull GH (1908). The composition of a field of maize. Ann. Breed. Assoc. 4: 296-301.

Song GS, Zhai HL, Peng YG, Zhang L, et al. (2010). Comparative transcriptional profiling and preliminary study on heterosis mechanism of super-hybrid rice. Mol. Plant 3: 1012-1025.Song R and Messing J (2003). Gene expression of a gene family in maize based on nonlinear haplotypes. Proc. Natl. Acad. Sci. U. S. A. 100: 9055-9060.

Song YP, Wang ZL, Zhang DQ, Ren Y, et al. (2012). Transcriptional profiling by cDNA-AFLP analysis showed differential transcript abundance in response to water stress in Populus hopeiensis. BMC Genomics 13: 286.

Stuber CW (1994). Heterosis in plant breeding. Plant Breed. Rev. 12: 227-251.

Stupar RM and Springer NM (2006). Cis-transcriptional variation in maize inbred lines B73 and Mo17 leads to additive expression patterns in the F1-hybrid. Genetics 173: 2199-2210.

Sun QX, Ni ZF and Liu ZY (1999). Differential gene expression between wheat hybrids and their parental inbreds in seedling leaves. Euphytica 106: 11-17.

Swanson-Wagner RA, Jia Y, DeCook R, Borsuk LA, et al. (2006). All possible modes of gene action are observed in a global comparison of gene expression in a maize F1-hybrid and its inbred parents. Proc. Natl. Acad. Sci. U. S. A. 103: 6805-6810.

Tian ZY and Dai JR (2003). Relationship between differential gene expression patterns in functional leaves of maize (Zea mays L.) at milk filling stage and heterosis using cDNA-AFLP. Chin. Sci. Bull. 48: 76-81.

Tsaftaris AS and Polidoros AN (1993). Studying the expression of genes in maize parental inbreds and their heterotic and non-heterotic hybrids. Proceedings of XVI Eucarpia Maize and Sorghum Conference, Bergamo, 283-292.

Tsaftaris AS and Kafka M (1998). Mechanisms of heterosis in crop plants. J. Crop Prod. 1: 95-111.

Uzarowska A, Keller B, Piepho HP, Schwarz G, et al. (2007). Comparative expression profiling in meristems of inbredhybrid triplets of maize based on morphological investigations of heterosis for plant height. Plant Mol. Biol. 63: 21-34.

Vos P, Hogers R, Bleeker M, Reijans M, et al. (1995). AFLP: a new technique for DNA fingerprinting. Nucleic Acids Res. 23: 4407-4414.

Vuylsteke M, Van Eeuwijk F, Van Hummelen P, Kuiper M (2005). Genetic analysis of variation in gene expression in Arabidopsis thaliana. Genetics 171: 1267-1275.

Wu LM, Ni ZF, Wang ZK, Lin Z, et al. (2001a). Relationship between differential expression patterns of multigene families and heterosis in a wheat diallel crosses. Acta Genet. Sin. 28: 256-266.

Wu LM, Ni ZF, Meng FR, Lin Z, et al. (2003). Cloning and characterization of leaf cDNAs that are differentially expressed between wheat hybrids and their parents. Mol. Gen. Genet. 270: 281-286.

Wu MS, Gao ZH and Dai JR (2001b). Studies on differential gene expression of maize (Zea mays L.) by means of cDNAAFLP technique. Acta Agronom. Sin. 27: 339-342.

Yao Y, Ni Z, Zhang Y, Chen Y, et al. (2005). Identification of differential expressed genes in leaf and root between wheat hybrid and its parental inbreds using PCR-based cDNA subtraction. Plant. Mol. Biol. 58: 367-384. 